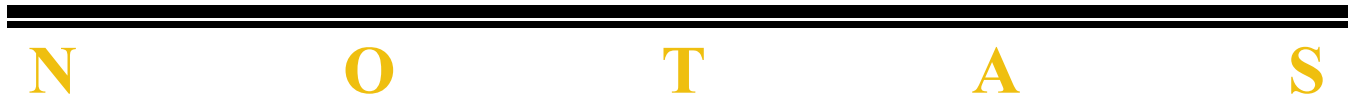




\section{LOS PRINCIPIOS JURÍDICOS SEGÚN MANUEL ATIENZA Y JUAN RUIZ MANERO}

\section{Principios en sentido estricto}

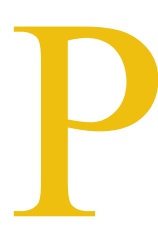

ermítaseme abordar sólo uno de los muchos problemas discutidos en Three Approaches to Legal Principles, de Manuel Atienza y Juan Ruiz Manero.

Atienza y Manero definen los principios en sentido estricto en términos del alcance de aplicación de una norma: un principio define los casos a los que cerrada». es aplicable «de forma abierta, mientras que las reglas lo hacen de forma

\section{Un ejemplo alexiano}

Permítaseme comparar esta teoría con un análisis de un ejemplo sueco a la luz de la teoría de Robert Alexy (cf. Peczenik, On Law and Reason, Dordrech / Boston / London: Kluwer, 1989, pp. 74 ss.). El Cap. 1 Sec. 2 de la Constitución sueca (Regerins formen) estipula lo que sigue: «El poder público debe ejercer con respeto al igual valor de todos los seres humanos y a la libertad y dignidad de cada persona individual». Esta disposición expresa tres principios, ya que quienes estén en el poder deben respetar (1) la igualdad, (2) la libertad y (3) la dignidad de cada individuo. Cada principio puede ser una razón prima-facie para la acción. Pero pueden colisionar de manera tal que, por ejemplo, un incremento de respeto por la igualdad en el caso particular de que se trate pueda causar una disminución de la libertad y viceversa. Se necesita entonces un acto de sopesar y ponderar para escoger entre ellos en un caso individual. 


\section{Una adaptación del ejemplo alexiano al lenguaje de Atienza-Manero}

Un aspecto de la teoría de Alexy puede expresarse en la terminología de Atienza-Manero de la siguiente manera: Un principio prima-facie establece un ideal que puede ser llevado a efecto en una cierta clase de casos, más o menos extensa. Para determinar la clase, se deben sopesar y ponderar varias razones prima-facie. Se debe, así, mirar a que, por ejemplo, un pequeño incremento del número de casos en los que prevalece la igualdad no cause una disminución demasiado grande del número de casos en los que prevalece la libertad; y tampoco un pequeño incremento del número de casos en los que la libertad vence debe pagarse con una disminución demasiado grande del número de casos en los que vence la igualdad.

\section{La principal diferencia entre las teorías}

Por otro lado, un principio alexiano nunca vence totalmente, por ejemplo, cuando prevalece la igualdad en un cierto caso, sigue existiendo no obstante alguna libertad. Esta forma de ver la colisión de principios en sentido estricto no es accesible a Atienza y Manero, dado que ellos asumen que tales principios no pueden ser cumplidos en diversos grados; véase sección 10 infra.

\section{Sopesar reglas}

¿Cómo afecta esta diferencia a la distinción entre reglas y principios? La cuestión es difícil porque no sólo los principios sino también algunas reglas crean un deber meramente prima-facie y por consiguiente exigen deliberación (esto es, sopesar y ponderar, cf. Peczenik, op. cit., pp. 80 ss.).

\section{Una distinción alexiana entre reglas y principios es posible a pesar de la necesidad de sopesar reglas}

En un lenguaje alexiano, se puede, entre otras cosas, indicar las siguientes diferencias entre reglas y principios.

1. En los casos rutinarios ("fáciles"), se deben seguir las reglas jurídicas socialmente establecidas sin ninguna necesidad de sopesar y ponderar. Por otra parte, ningún caso que implique principios es fácil. 
2. Hay grados de obediencia en relación con los principios. Por otra parte, una regla puede sólo ser obedecida o no. No hay grados de obediencia.

\section{7. ¿Es algún caso fácil?}

Ambas distinciones requieren discusión. Primero de todo, un acto de sopesar y ponderar es necesario para determinar si el caso bajo adjudicación es fácil o no. Atienza y Manero han afirmado lo siguiente: «Un caso es fácil precisamente cuando la subsunción de unos determinados hechos bajo una determinada regla no resulta controvertible a la luz del sistema de principios que dan sentido a la institución o sector normativo de que se trate».

\section{Las reglas jurídicas como razones amplificadoras}

Ellos extraen la siguiente conclusión. En el caso de las reglas jurídicas, «podemos hablar de una deliberación normativamente guiada [...], siendo admisible la toma en consideración de otras razones únicamente en la medida en que las propias pautas jurídicas lo permitan».

Me inclino a concordar con esta observación. Sin embargo, me parece que las «pautas jurídicas» permiten tomar en cuenta todas las consideraciones moralmente relevantes.

Por esa razón, permítaseme añadir lo siguiente: las normas jurídicas establecidas constituyen razones prima-facie, que han de ser sopesadas y ponderadas con otras razones. Estas razones prima-facie son razones de primer orden para la realización de una cierta acción, H, y, al mismo tiempo, razones de segundo orden. En esta última capacidad, indican que las razones para no hacer $\mathrm{H}$ pueden prevalecer sólo si son particularmente fuertes, esto es, claramente más fuertes de lo que necesitan ser en un debate moral libre (cf. On Law and Reason, op. cit., pp. 240 ss.).

\section{9. ¿Grados de cumplimiento de los principios?}

Por lo que respecta a la segunda distinción entre principios y reglas, los autores la rechazan explícitamente. Según ellos, «la tesis [de Alexy] de que los principios pueden ser cumplidos en diversos grados es verdadera por lo que se refiere a las directrices o normas programáticas, pero no lo es en el caso de los principios 
en sentido estricto». Considérese, por ejemplo, el art. 14 de la Constitución española: «los españoles son iguales ante la ley, sin que pueda prevalecer discriminación alguna por razón de nacimiento, raza, sexo, religión, opinión o cualquier otra condición o circunstancia personal o social». «La indeterminación característica de los principios la encontramos aquí únicamente en la configuración abierta de las condiciones de aplicación, pero no en la descripción de la conducta prohibida: discriminar». Atienza y Ruiz Manero rechazan también la asunción de Alexy de que los principios son mandatos de optimización: «los principios en sentido estricto son mandatos de optimización únicamente en el sentido de que, al estar configuradas de forma abierta sus condiciones de aplicación $[\ldots]$, pero una vez que se ha determinado que en ese caso prevalece el principio, éste exige un cumplimiento pleno».

Sin embargo, el ejemplo no falsa la teoría de Alexy, dado que el artículo 14 de la Constitución española es una regla (vaga), no un principio en el sentido de Alexy. Por otro lado, disposiciones tales como el Cap. 1 Sec. 2 de la Constitución sueca (véase supra, sección 2), que son principios en este sentido, pueden ser cumplidos en diversos grados.

\section{0. ¿No hay una distinción clara entre reglas y principios?}

Atienza y Manero proponen otra distinción, que es la siguiente: un principio en sentido estricto define los casos a los que es aplicable «de una manera abierta, mientras que las reglas lo hacen de una manera cerrada [...]: no se trata sólo de que las propiedades que constituyen las condiciones de aplicación tengan una periferia mayor o menor de vaguedad, sino de que tales condiciones no se encuentran siquiera genéricamente determinadas. El tipo de indeterminación que afecta a los principios es, pues, más radical que el de las reglas». En mi opinión, sin embargo, la distinción no es suficientemente clara. ¿En qué consiste esta radical indeterminación? No en la necesidad de pesar, que se aplica también a las reglas. Tampoco en la posibilidad de diferentes grados de cumplimiento de los principios, explícitamente negada por los autores. ¿En qué otra cosa, entonces?

\section{1. ¿Por qué principios?}

Con independencia de la respuesta que se dé a esta cuestión, hay que responder a otra cuestión más profunda. ¿Por qué son 
útiles los principios, en todo caso, en la justificación jurídica? Atienza y Manero indican que «los principios son [...] más que las reglas [...] en dos sentidos. Por un lado, porque al estar enunciados -o poder enunciarse- en términos más generales [...], tienen un mayor alcance justificatorio. Por otro lado, [...] [tienen] una mayor fuerza expansiva. Así, por ejemplo [...], a partir del principio de que "todos los españoles tienen derecho a una vivienda digna" conjuntamente con el enunciado de que "abaratar los créditos para viviendas facilita que un mayor número de personas acceda a una vivienda digna" puede concluirse, cuando menos, que "hay una razón para que el Estado abarate los créditos la compra de viviendas"».

Sin intentar explicar el término «fuerza expansiva», se puede indicar que la principal fuente de la fuerza justificatoria de los principios consiste en su vínculo uno-a-uno con los correspondientes valores. Cada principio corresponde a un valor determinado, estipula, por ejemplo, que la igualdad, la libertad y la dignidad son valiosas. Atienza y Manero se acercan a este punto, pues afirman que un principio en sentido estricto «expresa los valores superiores de un ordenamiento jurídico (que son el reflejo de una determinada forma de vida)».

Un valor puede ser definido como un criterio de valoración. Cada criterio puede satisfacerse hasta un cierto grado, mayor o menor (cfr. Alexy, Theorie der Grundrechte, Baden-Baden 1985: Nomos, pp. 130 ss.). Cada principio exige que el valor al que él mismo corresponde sea respetado tanto como sea posible.

Pero si éste es el caso, la posibilidad de cumplir principios en diversos grados, mayores o menores, es la propiedad más esencial de los principios. Y Alexy tiene razón, mientras que la crítica de Atienza y Manero a su teoría no es suficientemente profunda.

Por otra parte, los principios en sentido estricto, según Atienza y Manero, pueden ser útiles, también, cuando el legislador tiene una razón para hacer una regla «fija» que resulte aplicable a un conjunto «no fijo» de casos, como ocurre por ejemplo en el supuesto de las cláusulas generales. Una pregunta interesante es la de cuáles son las condiciones que hacen justificable esta clase de legislación. 